OPEN ACCESS

Edited by:

Geoffrey E. Hill,

Auburn University, USA

Reviewed by:

Vincent Alexandre Viblanc,

Institut PluriDisciplinaire Hubert Curien

(CNRS), France

Lynn Marie Siefferman,

Appalachian State University, USA

*Correspondence: Michaël Beaulieu miklvet@hotmail.fr

Specialty section:

This article was submitted to Behavioral and Evolutionary Ecology,

a section of the journal

Frontiers in Ecology and Evolution

Received: 20 September 2016 Accepted: 07 December 2016 Published: 22 December 2016

Citation: Beaulieu M (2016) A Bird in the House: The Challenge of Being Ecologically Relevant in Captivity.

Front. Ecol. Evol. 4:141. doi: 10.3389/fevo.2016.00141

\section{A Bird in the House: The Challenge of Being Ecologically Relevant in Captivity}

\author{
Michaël Beaulieu * \\ Zoological Institute and Museum, University of Greifswald, Greifswald, Germany
}

Ecologists have acknowledged the fact that environmental conditions strongly affect life-history strategies in the wild. However, when working in captivity, they appear to overlook these effects. This approach appears precarious, as it likely contributes to increase the inconsistency of results across ecological studies. To illustrate this point, I reviewed here the conditions under which captive zebra finches (Taeniopygia guttata) are kept in studies examining stress parameters that mediate life-history strategies, and compared these conditions to the conditions their wild counterparts experience in their native habitat. I found that captive zebra finches are typically kept under conditions that mostly reflect a paradoxical season in terms of temperature, light and humidity that would never be encountered in the wild. Most importantly, I also found that these conditions are associated with elevated stress levels. This suggests that most studies using captive zebra finches are conducted under stressful conditions, and therefore give a biased and limited view of how birds regulate life-history strategies. This example strongly suggests that we have to rethink our approach when examining ecological questions in captivity, by carefully considering conditions under which animals are kept in view of their current and future ecology.

Keywords: captivity, corticosterone, ethics, housing conditions, oxidative stress

\section{INTRODUCTION}

Guidelines regarding the housing of laboratory animals are sometimes vague, especially concerning non-model organisms. For instance, the Directive 2010/63/EU states that "temperature and relative humidity [...] shall be adapted to the species" and that "regular photoperiods and intensity of light adapted to the species shall be provided" (European Parliament and the Council of the European Union, 2010). These sentences are equivocal, as the meaning of the word "adapted" can be understood differently. Does it mean that animals should be housed under the least stressful conditions, under conditions that they would encounter in the wild, or under the minimal conditions enabling them to survive in captivity? These semantic differences are of prime importance in ecological studies, as animals may allocate resources differently based on the environmental conditions they experience (Stearns, 1989). For instance, animals housed under the least stressful conditions are likely to allocate resources to self-maintenance and reproduction alike (Ricklefs and Cadena, 2007), while animals housed under environmental conditions limiting resource availability are likely to trade-off reproduction against self-maintenance (Beaulieu et al., 2015). This shows that the vagueness surrounding the formulation of guidelines for the housing of laboratory animals are likely to lead to a great variability of conditions under which captive 
animals are monitored, which in turn is likely to lead to inconsistent or even contradictory results in ecological studies.

Here, I reviewed the conditions under which captive zebra finches (Taeniopygia guttata) are housed, and compared these conditions to the conditions their wild counterparts experience in Australia (Methods and Raw Data in Supplemental Material). Zebra finches are highly relevant in this context, as they represent one of the most common avian models in captivity, with an increasing interest for these birds in ecology and evolution (Bateson and Feenders, 2010; Griffith and Buchanan, 2010; Schmidt, 2010). Presumably because selective pressures are relaxed in captivity, captive and wild animals differ in several traits, with captive birds typically being genetically less diverse, larger, heavier, more colorful, less discriminating during courtship, and less active than wild birds (Sossinka, 1982; Forstmeier et al., 2007). However, captive and wild zebra finches appear to use very similar resource allocation strategies and investment priorities when conditions vary, thereby making them highly comparable for ecologists examining their lifehistory strategies (Tschirren et al., 2009; Mainwaring et al., 2010).

In this review, I focused on articles examining in zebra finches physiological markers of stress that are likely to mediate life-history strategies, such as glucocorticoids (corticosterone) and markers of oxidative stress (Monaghan et al., 2009; Crespi et al., 2013). These markers are currently receiving much attention in ecological studies (Wingfield, 2013a,b; Beaulieu and Costantini, 2014; Dantzer et al., 2014; Speakman et al., 2015; Taff and Vitousek, 2016). Corticosterone is secreted once the life-emergency stage is activated to allow animals to cope with stressful conditions. It redirects the physiology and the behavior of animals to reduce the cost (i.e., allostatic load) triggered by stressful conditions (Wingfield, 2013a,b). Oxidative stress occurs when the production of reactive oxygen species surpasses antioxidant defenses and increases oxidative damage, which in turn can negatively affect fitness components (Costantini, 2008; Monaghan et al., 2009). Oxidative stress is typically exacerbated by stressful environmental conditions (Beaulieu and Costantini, 2014). Because oxidative stress can also accelerate the shortening of telomeres (non-coding sequences of a repeated motif that cap the ends of chromosomes; von Zglinicki, 2002), I also included in this review studies on telomeres, which can themselves be considered as markers of physiological stress (Bateson, 2016).

\section{DO CONDITIONS IN CAPTIVITY REFLECT NATURAL CONDITIONS?}

Based on the superposition of the current distribution range of zebra finches (IUCN, 2015) to the major climatic zones of Australia (Australian Government Bureau of Meteorology, 2014), the desert, the grassland, and the subtropical zones appear the most suitable habitats for zebra finches, as these zones are almost entirely occupied by birds. In contrast, the tropical and the temperate zones appear as suboptimal habitats, as they are only partly occupied, while the equatorial zone is unsuitable, as it is entirely devoid of zebra finches (Figure 1).

The average temperature used in studies conducted with zebra finches in captivity (mean $\pm \mathrm{SD}=22.2 \pm 2.0^{\circ} \mathrm{C}$ ) corresponds to the average temperature occurring during spring and fall equinoxes in the three most suitable climatic zones, during the winter months in the tropical zone, and during the summer months in the temperate zone (Figure 1). This suggests that the temperature conditions used in captivity are representative of a very brief period of time when considering the three most suitable climatic zones, but reflect longer periods of time in suboptimal zones. This first shows that thermal conditions in captivity are representative of geographically and seasonally limited conditions in the wild.

The combination of the temperature and light conditions used in captivity (mean $\pm \mathrm{SD}=13.8 \pm 1.4$ hours/day) reveals a seasonal mismatch between these parameters, at least when considering the three most suitable climatic zones. Indeed, a temperature of $22^{\circ} \mathrm{C}$ corresponds to equinoxes while 14-h long days correspond to the summer solstice (Figure 1). Importantly, this mismatch is expected to worsen in the future. Indeed, as temperatures are expected to increase in the next decades in the three most suitable climatic zones for zebra finches (CSIRO, 2015), birds are likely to encounter in the future a mean temperature of $22^{\circ} \mathrm{C}$ in a season characterized by shorter days (Figure S1). Temperature and light conditions in captivity do not reflect either the conditions occurring in the tropical zone. Indeed, the light schedule used in captivity never occurs in the tropical zone and, even though the temperature used in captivity reflects current winter temperatures, such a temperature is unlikely to be encountered in the future in this region (Figure S1). In the end, the conditions used in captivity appear to best match summer conditions in the temperate zone in terms of temperature and light. However, the humidity used in captivity (mean $\pm \mathrm{SD}=45.8 \pm 11.4 \%$ ) is never encountered in this climatic zone. This suggests that, overall, captive zebra finches are housed under conditions that would be perceived as a paradoxical season in the wild. This is reinforced by the fact that day length and temperature are not correlated in captivity while they are strongly correlated in the wild (Figure S2).

\section{ARE CONDITIONS IN CAPTIVITY STRESSFUL?}

It might be argued that captive zebra finches have become more tolerant to cool conditions through decades of domestication, which should have decreased their lower critical temperature (temperature under which energy requirements linearly increase for thermoregulation). However, captive birds do not show a reduced lower critical temperature compared to (mostly) wild birds (Calder, 1964; Marschall and Prinzinger, 1991), and their metabolic rate more than doubles between thermoneutral temperatures $\left(32-34^{\circ} \mathrm{C}\right)$ and cooler conditions $\left(13-15^{\circ} \mathrm{C}\right)$ (Bauchinger et al., 2010; Burness et al., 2010; BeamonteBarrientos and Verhulst, 2013), similarly to (mostly) wild birds (Calder, 1964). This shows that the thermal tolerance of zebra finches was not altered by domestication. Therefore, keeping zebra finches under conditions mostly cooler than the thermal conditions they encounter in their natural habitat is likely to be a 

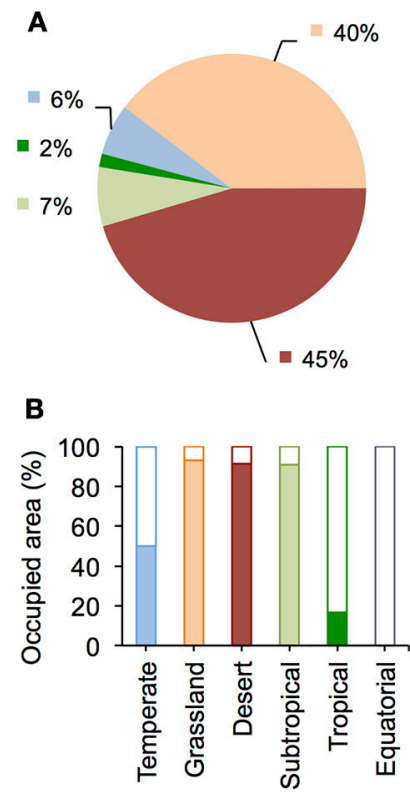
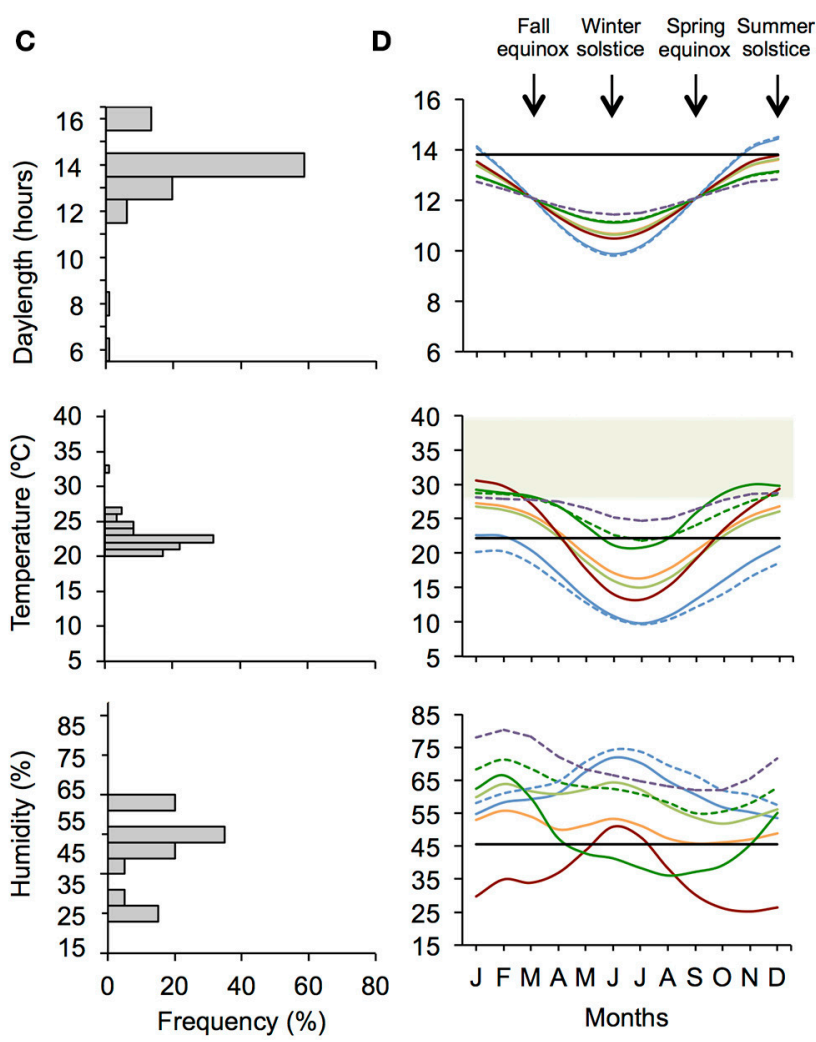

FIGURE 1 | Distribution range of zebra finches in the different climatic zones of Australia, and conditions experienced by captive and wild zebra finches. Blue represents the temperate zone, orange the grassland, red the desert, light green the subtropical zone, dark green the tropical zone, and purple the equatorial zone. (A) Shows how the whole territory occupied by zebra finches is divided between these climatic zones. (B) Shows the proportion of each climatic zone occupied by zebra finches (colored bar) and the proportion where they are absent (empty bar). The conditions used by studies in captivity are represented in (C), and conditions in the wild are represented in (D). Annual variation of these conditions in the wild is represented for each of the climatic zones of Australia. Solid lines represent regions where zebra finches are present, while dashed lines represent regions where they are absent in partly-occupied climatic zones (between 0 and $50 \%$ of the total area). The temperate subzone where zebra finches are absent is significantly colder than the temperate subzone where they are present especially in summer [subzone: $F_{(1,85)}=19.733, P<0.001$; month: $F_{(1,128)}=823.183, P<0.001$; month ${ }^{2}: F_{(1,128)}=746.831, P<0.001$; subzone*month: $F_{(1,128)}=$ 13.976, $P<0.001$; subzone month $\left.^{2}: F_{(1,128)}=13.857, P<0.001\right]$. The tropical subzone where birds are absent is significantly more humid than the tropical subzone where they are present especially outside the rain season (winter) [subzone: $F_{(1,12)}=1.395, P=0.261 ;$ month: $F(1,95)=108.776, P<0.001 ;$ month ${ }^{2}$ : $F_{(1,95)}=77.266, P<0.001$; subzone ${ }^{\star}$ month: $F_{(1,95)}=38.213, P<0.001$; subzone ${ }^{\star}$ month $\left.{ }^{2}: F_{(1,95)}=33.411, P<0.001\right]$ while temperatures are similarly high in the two subzones [subzone: $F_{(1,12)}=0.303, P=0.587$; month: $F_{(1,95)}=223.947, P<0.001$, month ${ }^{2}: F_{(1,95)}=228.133, P<0.001$; subzone ${ }^{\star}$ month: $F_{(1,95)}=$ 1.637, $P=0.204$; subzone*month $\left.{ }^{2}: F_{(1,95)}=3.486, P=0.065\right]$. The black horizontal lines represent average conditions used in captivity. The green area represents the thermoneutral zone of zebra finches (i.e., the temperature range outside which energy requirements increase for thermoregulation).

source of stress for birds. Accordingly, a review of the literature shows that captive zebra finches kept under cooler conditions show higher baseline corticosterone levels (temperature range: $20.0-26.5^{\circ} \mathrm{C}$, Figure $2 \mathrm{~A}$ ). These results are in agreement with previous studies examining the effects of cool conditions on corticosterone levels in wild-caught European starlings (Sturnus vulgaris; de Bruijn and Romero, 2011, 2013). This suggests that most studies keeping zebra finches between 20 and $22^{\circ} \mathrm{C}(72 \%$ of studies) keep birds under thermally-stressful conditions. These temperatures (or even lower temperatures) are, however, also found in each of the climatic zones occupied by zebra finches, and especially in the temperate zone where such thermal conditions occur year round (Figure 1). This suggests that each climatic zone is at least temporarily thermally-stressful for zebra finches. Interestingly, the temperate subzone where zebra finches are absent is significantly colder than the temperate subzone where they are present (Figure 1D), suggesting that cold-induced stress is likely to contribute to the absence of zebra finches in this climatic zone.

In captive zebra finches, corticosterone levels also depend on the interaction between temperature and humidity, with higher corticosterone levels being found with high temperature and humidity (Figure 2B). Given the small number of studies reporting information on corticosterone levels and humidity ( $n=14$ ), these results need to be considered with caution. However, the distribution range of zebra finches in the tropical zone appears to support them. Indeed, the tropical subzone where birds are absent is significantly more humid than the tropical subzone where they are present while temperatures are similarly high in the two subzones (Figure 1D). This suggests 

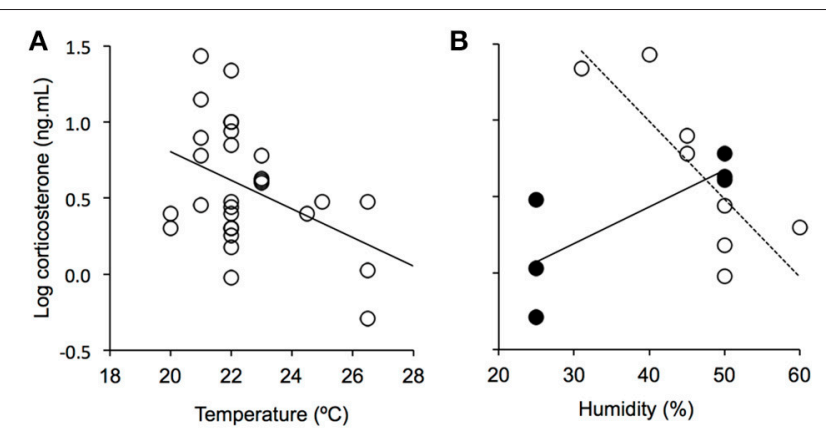

FIGURE 2 | Effects of conditions in captivity on corticosterone levels in zebra finches. The relationship between corticosterone levels and

temperature is represented in (A), and the relationship between corticosterone levels and humidity is represented in (B). Corticosterone levels depend on temperature $\left[F_{(1,27)}=5.531, P=0.026, \mathbf{A}\right]$, and on the interaction between temperature and humidity [humidity: $F_{(1,10)}=5.754, P=0.037$; temperature: $F_{(1,10)}=10.146, P=0.010$; humidity ${ }^{\star}$ temperature: $F_{(1,10)}=5.027, P=$ $0.049, \mathbf{B}]$. For the visualization of the effects of the interaction between humidity and temperature on corticosterone levels, data have been artificially divided between $\left[21-22^{\circ} \mathrm{C}\right.$ ] (white symbols) and [23-26.5 ${ }^{\circ} \mathrm{C}$ ] (black symbols).

that stress induced by the combined effects of heat and humidity may contribute to the absence of zebra finches in the tropical zone.

These results suggest that the climatic zones at the edge of the current distribution range of zebra finches (i.e., temperate and tropical zones) correspond to suboptimal habitats, across which costs progressively surpass benefits. This suggests that zebra finches able to live in the tropical and the temperate zones may correspond to atypical birds able to maximize benefits relative to costs under suboptimal conditions (Wingfield et al., 2015). Consequently, using conditions currently occurring in the tropical or the temperate zone as a reference for studies conducted in captivity is unlikely to give a representative picture of the bulk of the species.

I was not able to examine the effects of thermal conditions on other stress parameters than corticosterone, such as markers of oxidative status that were too heterogeneous. However, such effects can be expected. Indeed, zebra finches exposed $24 \mathrm{~h}$ at $12^{\circ} \mathrm{C}$ show higher levels of oxidative damage than individuals kept at $24^{\circ} \mathrm{C}$ (Stier et al., 2014) (although such effects do not occur for a shorter cold exposure; Beamonte-Barrientos and Verhulst, 2013). At the same time, zebra finches exposed to cold conditions appear to mobilize antioxidant compounds, as after $48 \mathrm{~h}$ at $6^{\circ} \mathrm{C}$, they show higher plasma carotenoid concentrations than individuals kept at $26^{\circ} \mathrm{C}$ (Eraud et al., 2007). It might be argued that such effects may not be observed in captive zebra finches that are kept under thermal conditions not as extreme as in these examples (typically $22^{\circ} \mathrm{C}$ ). However, similar to the study conducted on zebra finches at $6^{\circ} \mathrm{C}$ (Eraud et al., 2007), a study conducted in gouldian finches (Erythrura gouldiae) at a milder temperature $\left(20^{\circ} \mathrm{C}\right)$ showed that birds kept at that temperature also increase antioxidant defenses relative to birds kept within their thermoneutral zone (Beaulieu et al., 2014). This suggests that, similar to corticosterone levels, the thermal conditions under which captive zebra finches are kept are likely to affect their oxidative status.

Because of limited data, I was not able to examine the effects of long days on stress parameters in zebra finches. However, studies conducted in other birds indicate that long days can be perceived as stressful. For instance, in the neotropical yellow-rumped warbler (Dendroica coronata), basal corticosterone levels increase with daylight duration (Holberton, 1999). Moreover, prolonged exposure to light is also likely to worsen the oxidative status of birds (Navara and Nelson, 2007). The fact that prolonged exposure to light may negatively affect the self-maintenance of zebra finches is reinforced by the fact that their mortality rate significantly increases when they are exposed to continuous daylight (Snyder et al., 2013). These stressful effects are likely to be due to the fact that long days can disrupt the sleep of birds (Raap et al., 2015). As sleep allows birds to conserve energy (Roth et al., 2010), this suggests that long days are likely to aggravate the increased energy requirements and stress due to cool conditions.

\section{WHAT ARE THE CONSEQUENCES OF KEEPING CAPTIVE ANIMALS UNDER STRESSFUL CONDITIONS IN ECOLOGICAL STUDIES?}

Keeping animals under suboptimal conditions (e.g., cool conditions) may not necessarily be a drawback in ecological studies, as it forces animals to allocate resources between functions. Consequently, it represents an excellent opportunity for ecologists to examine how animals regulate life-history trade-offs. For instance, captive zebra finches exposed to a low temperature $\left(7^{\circ} \mathrm{C}\right)$ maintain body condition but their reproduction performance is greatly impaired relative to birds exposed to $21^{\circ} \mathrm{C}$ (Salvante et al., 2007). Accordingly, in contrast to birds from the center of Australia, birds from the cooler temperate zone cannot maintain an activated reproductive system year-round (Perfito et al., 2007). These effects may be mediated by elevated corticosterone levels, as experimentally increasing corticosterone levels in captive zebra finches also impairs their breeding performance (Salvante and Williams, 2003). These results suggest that captive and wild zebra finches both reduce investment into reproduction under cool conditions presumably to maintain body condition. As most studies on captive zebra finches are conducted under this ecological scenario, this reveals a strong bias in the results of these studies. Moreover, most of these studies do not have a control group of birds exposed to higher temperatures (or even better to temperatures within their thermoneutral zone), thereby making the interpretation of results difficult. At least, investigators should report the thermal conditions under which animals are kept (38\% of studies do not report such information) in order to be able to estimate how stressful conditions are, and how animals regulate life-history trade-offs. This is also true regarding humidity conditions. Indeed, in the wild, zebra finches use relative humidity as a signal for breeding. Accordingly, subtle changes in humidity (40-55\%) appear to have strong effects on their reproductive performance in captivity, with higher humidity 
triggering higher reproductive performance (Williamson et al., 2008). In the few studies conducted on captive zebra finches and reporting information on humidity (15\% of studies), mean humidity greatly fluctuates (25-60\%), thereby suggesting that the readiness of zebra finches to reproduce (and how they regulate life-history trade-offs) is likely to greatly vary across studies.

Importantly, the effects of captive conditions on the physiology of zebra finches reported here are likely to affect in turn their behavior. For instance, male zebra finches with high corticosterone levels are unlikely to be selected by females to mate (Roberts et al., 2007), while high corticosterone levels is likely to induce greater exploratory behavior and greater risk taking (Martins et al., 2007). As there is no reason to think that zebra finches used in behavioral studies are housed under conditions less stressful than those reported here, this indicates that most behavioral studies also only give a biased and limited view of the full behavioral spectrum of these birds. Such concern has already been raised in neurobiological sciences (Schmidt, 2010).

\section{WHY DO INVESTIGATORS USE SUCH CONDITIONS IN CAPTIVITY?}

The absence of precise recommendations regarding the conditions under which captive zebra finches should be kept is likely to explain why these conditions appear to vary arbitrarily from a study to another. The only recommendation that I found regarding the thermal conditions under which zebra finches should be kept is given by the Royal Society for the Prevention of Cruelty to Animals (RSPCA), which recommends that "zebra finches should be housed at a temperature comprised between 15 and $20^{\circ}$ C" (RSPCA Research Animal Department, 2011). Here, the concern is not that these thermal conditions may correspond to any actual ecological situation, but that birds could be exposed to a risk of hypothermia at lower temperatures. Overall, the absence of precise guidelines gives much leeway to ethics committees and investigators regarding the settings they want to use. Moreover, ethics committees may not necessarily have the expertise regarding the requirements of non-model animals such as zebra finches, which may lead to the decision to keep birds under the same conditions as those typically used for model organisms (e.g., rodents) or for local birds.

The vast majority of studies using zebra finches are conducted in institutions of Europe and North America. In these regions, birds typically breed in spring or summer, when temperatures are close to the thermal conditions reported here for captive zebra finches. This suggests that investigators are likely to consider temperate conditions as a reference and extend them to non-temperate regions (Zuk, 2016). This is reinforced by the fact that captive zebra finches are mostly maintained under long days, although photoperiodicity does not appear to trigger reproduction in this species (as opposed to temperate birds;
Perfito, 2010; Olson et al., 2014). This temperate bias is therefore likely to explain why the conditions in captivity better reflect the environmental conditions of the temperate zone of Australia, although this climatic zone appears suboptimal for zebra finches.

\section{CONCLUDING REMARKS AND PERSPECTIVES}

By using the example of studies examining stress parameters in captive zebra finches, the present review highlights the fact that ecological studies often overlook the effects of environmental conditions on the regulation of life-history strategies in captive animals. The current approach consisting in considering these environmental factors as marginal details in captivity appears precarious, as it likely contributes to the inconsistency of results that we currently observe across ecological studies. For instance, studies examining whether variation in oxidative status may mediate life-history strategies have produced highly inconsistent results, thereby casting doubt on the generality of findings (Speakman et al., 2015).

Except adverse conditions that affect animal welfare, there are no wrong conditions under which animals can be kept in captivity, but only conditions reflecting more or less a given situation in the wild. Future studies conducted in captivity should therefore not necessarily try to follow common procedural guidelines (Schmidt, 2010) but consider the conditions that they use in view of the current and future ecology of the considered species. This suggests that, similar to conditions in the wild, environmental conditions can also be stressful in captivity. In that case, investigators need to be aware and acknowledge that these conditions are stressful (and not try to dismiss this fact). Consequently, when deciding about which conditions to use in captivity, the main question should be: are the parameters representative of the natural conditions encountered by animals in space and time, and is this combination of parameters stressful? Only this simple but more rigorous approach will allow us to reconcile ecological studies and captivity.

\section{AUTHOR CONTRIBUTIONS}

$\mathrm{MB}$ reviewed literature, made analyses, and wrote the manuscript.

\section{FUNDING}

MB received financial support from the University of Greifswald.

\section{SUPPLEMENTARY MATERIAL}

The Supplementary Material for this article can be found online at: http://journal.frontiersin.org/article/10.3389/fevo. 2016.00141/full\#supplementary-material 


\section{REFERENCES}

Australian Government Bureau of Meteorology (2014). Climate zones. Available online at: http://www.bom.gov.au/iwk/climate_zones/map_1.shtml (Accessed June 20, 2006).

Bateson, M. (2016). Cumulative stress in research animals: telomere attrition as a biomarker in a welfare context? Bioessays 38, 201-212. doi: 10.1002/ bies. 201500127

Bateson, M., and Feenders, G. (2010). The use of passerine bird species in laboratory research: implications of basic biology for husbandry and welfare. ILAR J. 51, 394-408. doi: 10.1093/ilar.51.4.394

Bauchinger, U., Keil, J., McKinney, R. A., Starck, J. M., and McWilliams, S. R. (2010). Exposure to cold but not exercise increases carbon turnover rates in specific tissues of a passerine. J. Exp. Biol. 213, 526-534. doi: 10.1242/jeb.037408

Beamonte-Barrientos, R., and Verhulst, S. (2013). Plasma reactive oxygen metabolites and non-enzymatic antioxidant capacity are not affected by an acute increase of metabolic rate in zebra finches. J. Comp. Physiol. B 183, 675-683. doi: 10.1007/s00360-013-0745-4

Beaulieu, M., and Costantini, D. (2014). Biomarkers of oxidative status: missing tools in conservation physiology. Conserv. Physiol. 2:cou014. doi: 10.1093/conphys/cou014

Beaulieu, M., Geiger, R. E., Reim, E., Zielke, L., and Fischer, K. (2015). Reproduction alters oxidative status when it is traded-off against longevity. Evolution 69, 1786-1796. doi: 10.1111/evo.12697

Beaulieu, M., Haas, A., and Schaefer, H. M. (2014). Self-supplementation and effects of dietary antioxidants during acute thermal stress. J. Exp. Biol. 217, 370-375. doi: 10.1242/jeb.092825

Burness, G., Armstrong, C., Fee, T., and Tilman-Schindel, E. (2010). Is there an energetic-based trade-off between thermoregulation and the acute phase response in zebra finches? J. Exp. Biol. 213, 1386-1394. doi: 10.1242/jeb.027011

Calder, W. A. (1964). Gaseous metabolism and water relations of the zebra finch, Taeniopygia castanotis. Physiol. Zool. 37, 400-413. doi: $10.1086 /$ physzool.37.4.30152758

Costantini, D. (2008). Oxidative stress in ecology and evolution: lessons from avian studies. Ecol. Lett. 11, 1238-1251. doi: 10.1111/j.1461-0248.2008.01246.x

Crespi, E. J., Williams, T. D., Jessop, T. S., and Delehanty, B. (2013). Life history and the ecology of stress: how do glucocorticoid hormones influence life-history variation in animals? Funct. Ecol. 27, 93-106. doi: 10.1111/1365-2435.12009

CSIRO (2015). Climate Change in Australia. Available online at: http://www. climatechangeinaustralia.gov.au/en/ (Accessed June 20, 2006).

Dantzer, B., Fletcher, Q. E., Boonstra, R., and Sheriff, M. J. (2014). Measures of physiological stress: a transparent or opaque window into the status, management and conservation of species? Conserv. Physiol. 2, 1-18. doi: 10.1093/conphys/cou023

de Bruijn, R., and Romero, L. M. (2011). Behavioral and physiological responses of wild-caught European starlings (Sturnus vulgaris) to a minor, rapid change in ambient temperature. Comp. Biochem. Physiol. A Mol. Integr. Physiol. 160, 260-266. doi: 10.1016/j.cbpa.2011.06.011

de Bruijn, R., and Romero, L. M. (2013). Artificial rain and cold wind act as stressors to captive molting and non-molting European starlings (Sturnus vulgaris). Comp. Biochem. Physiol. A Mol. Integr. Physiol. 164, 512-519. doi: 10.1016/j.cbpa.2012.12.017

Eraud, C., Devevey, G., Gaillard, M., Prost, J., Sorci, G., and Faivre, B. (2007). Environmental stress affects the expression of a carotenoid-based sexual trait in male zebra finches. J. Exp. Biol. 210, 3571-3578. doi: 10.1242/jeb.005496

European Parliament and the Council of the European Union (2010). Directive 2010/63/EU of the European Parliament and of the Council of 22 September 2010 on the protection of animals used for scientific purposes. Off. J. Eur. Union 276, 33-79.

Forstmeier, W., Segelbacher, G., Mueller, J. C., and Kempenaers, B. (2007). Genetic variation and differentiation in captive and wild zebra finches (Taeniopygia guttata). Mol. Ecol. 16, 4039-4050. doi: 10.1111/j.1365-294X.2007.03444.x

Griffith, S. C., and Buchanan, K. L. (2010). The zebra finch: the ultimate Australian supermodel. Emu 110, 5-12. doi: 10.1071/MUv110n3_ED

Holberton, R. L. (1999). Changes in patterns of corticosterone secretion concurrent with migratory fattening in a neotropical migratory bird. Gen. Comp. Endocrinol. 116, 49-58. doi: 10.1006/gcen.1999.7336
IUCN (2015). The IUCN Red List of Threatened Species - Version 2015-4. Available online at: http://maps.iucnredlist.org/map.html?id=22719679 (Accessed June 20, 2006).

Mainwaring, M. C., Hartley, I. R., Gilby, A. J., and Griffith, S. C. (2010). Hatching asynchrony and growth trade offs within domesticated and wild zebra finch broods. Biol. J. Linn. Soc. 100, 763-773. doi: 10.1111/j.1095-8312.2010.01460.x

Marschall, U., and Prinzinger, R. (1991). Vergleichende Ökophysiologie von fünf Prachtfinkenarten (Estrildidae). J. Ornithol. 3, 319-323. doi: 10.1007/BF01640540

Martins, T. L., Roberts, M. L., Giblin, I., Huxham, R., and Evans, M. R. (2007). Speed of exploration and risk-taking behavior are linked to corticosterone titres in zebra finches. Horm. Behav. 52, 445-453. doi: 10.1016/j.yhbeh.2007.06.007

Monaghan, P., Metcalfe, N. B., and Torres, R. (2009). Oxidative stress as a mediator of life history trade-offs: mechanisms, measurements and interpretation. Ecol. Lett. 12, 75-92. doi: 10.1111/j.1461-0248.2008.01258.x

Navara, K. J., and Nelson, R. J. (2007). The dark side of light at night: physiological, epidemiological, and ecological consequences. J. Pineal Res. 43, 215-224. doi: 10.1111/j.1600-079X.2007.00473.x

Olson, C., Wirthlin, M., Lovell, P. V., and Mello, C., V (2014). Proper care, husbandry, and breeding guidelines for the zebra finch, Taeniopygia guttata. Cold Spring Harb. Protoc. 12, 1243-1248. doi: 10.1101/pdb.prot084780

Perfito, N. (2010). The reproductive and stress physiology of zebra finches in context: integrating field and laboratory studies. Emu 110, 199-208. doi: 10.1071/MU09091

Perfito, N., Zann, R. A., Bentley, G. E., and Hau, M. (2007). Opportunism at work: habitat predictability affects reproductive readiness in free-living zebra finches. Funct. Ecol. 21, 291-301. doi: 10.1111/j.1365-2435.2006.01237.x

Raap, T., Pinxten, R., and Eens, M. (2015). Light pollution disrupts sleep in free-living animals. Sci. Rep. 5:13557. doi: 10.1038/srep13557

Ricklefs, R. E., and Cadena, C. D. (2007). Lifespan is unrelated to investment in reproduction in populations of mammals and birds in captivity. Ecol. Lett. 10, 867-872. doi: 10.1111/j.1461-0248.2007.01085.x

Roberts, M. L., Buchanan, K. L., Bennett, A. T. D., and Evans, M. R. (2007). Mate choice in zebra finches: does corticosterone play a role? Anim. Behav. 74, 921-929. doi: 10.1016/j.anbehav.2006.12.021

Roth, T. C. II., Rattenborg, N. C., and Pravosudov, V., V (2010). The ecological relevance of sleep: the trade-off between sleep, memory and energy conservation. Philos. Trans. R. Soc. Lond. B Biol. Sci. 365, 945-959. doi: 10.1098/rstb.2009.0209

RSPCA Research Animal Department (2011). Zebra Finches: Good Practice for Housing and Care. Available online at: http://www.rspca.org.uk/ researchanimals

Salvante, K. G., Walzem, R. L., and Williams, T. D. (2007). What comes first, the zebra finch or the egg: temperature-dependent reproductive, physiological and behavioural plasticity in egg-laying zebra finches. J. Exp. Biol. 210, 1325-1334. doi: 10.1242/jeb.02745

Salvante, K. G., and Williams, T. D. (2003). Effects of corticosterone on the proportion of breeding females, reproductive output and yolk precursor levels. Gen. Comp. Endocrinol. 130, 205-214. doi: 10.1016/S0016-6480(02)00637-8

Schmidt, M. F. (2010). An IACUC perspective on songbirds and their use in neurobiological research. ILAR J. 51, 424-430. doi: 10.1093/ilar.51.4.424

Snyder, J. M., Molk, D. M., and Treuting, P. M. (2013). Increased mortality in a colony of zebra finches exposed to continuous light. J. Am. Assoc. Lab. Anim. Sci. 52, 301-307.

Sossinka, R. (1982). "Domestication in birds," in Avian Biology, eds D. Farner, J. King, and K. Parkes (New York, NY: Academic Press), 373-403.

Speakman, J. R., Blount, J. D., Bronikowski, A. M., Buffenstein, R., Isaksson, C., Kirkwood, T. B., et al. (2015). Oxidative stress and life histories: unresolved issues and current needs. Ecol. Evol. 5, 5745-5757. doi: 10.1002/ece3.1790

Stearns, S. C. (1989). Trade-offs in life-history evolution. Funct. Ecol. 3, 259-268. doi: $10.2307 / 2389364$

Stier, A., Massemin, S., and Criscuolo, F. (2014). Chronic mitochondrial uncoupling treatment prevents acute cold-induced oxidative stress in birds. J. Comp. Physiol. B 184, 1021-1029. doi: 10.1007/s00360-014-0856-6

Taff, C. C., and Vitousek, M. N. (2016). Endocrine flexibility: optimizing phenotypes in a dynamic world? Trends Ecol. Evol. 31, 476-488. doi: 10.1016/j.tree.2016.03.005 
Tschirren, B., Rutstein, A. N., Postma, E., Mariette, M., and Griffith, S. C. (2009). Short- and long-term consequences of early developmental conditions: a case study on wild and domesticated zebra finches. J. Evol. Biol. 22, 387-395. doi: 10.1111/j.1420-9101.2008.01656.x

von Zglinicki, T. (2002). Oxidative stress shortens telomeres. Trends Biochem. Sci. 27, 339-344. doi: 10.1016/S0968-0004(02)02110-2

Williamson, K., Gilbert, L., Rutstein, A. N., Pariser, E. C., and Graves, J. A. (2008). Within-year differences in reproductive investment in laboratory zebra finches (Taeniopygia guttata), an opportunistically breeding bird. Naturwissenschaften 95, 1143-1148. doi: 10.1007/s00114-008-0436-2

Wingfield, J. C. (2013a). Ecological processes and the ecology of stress: the impacts of abiotic environmental factors. Funct. Ecol. 27, 37-44. doi: 10.1111/1365-2435.12039

Wingfield, J. C. (2013b). The comparative biology of environmental stress: Behavioural endocrinology and variation in ability to cope with novel, changing environments. Anim. Behav. 85, 1127-1133. doi: 10.1016/j.anbehav. 2013.02.018
Wingfield, J. C., Krause, J. S., Perez, J. H., Chmura, H. E., Németh, Z., Word, K. R., et al. (2015). A mechanistic approach to understanding range shifts in a changing world: what makes a pioneer? Gen. Comp. Endocrinol. 222, 44-53. doi: 10.1016/j.ygcen.2015.08.022

Zuk, M. (2016). Temperate assumptions: how where we work influences how we think. Am. Nat. 188, 1-7. doi: 10.1086/687546

Conflict of Interest Statement: The author declares that the research was conducted in the absence of any commercial or financial relationships that could be construed as a potential conflict of interest.

Copyright (C) 2016 Beaulieu. This is an open-access article distributed under the terms of the Creative Commons Attribution License (CC BY). The use, distribution or reproduction in other forums is permitted, provided the original author(s) or licensor are credited and that the original publication in this journal is cited, in accordance with accepted academic practice. No use, distribution or reproduction is permitted which does not comply with these terms. 